Somnologie $2021 \cdot 25: 197-204$

https://doi.org/10.1007/s11818-021-00320-w

Received: 29 January 2021

Accepted: 4 July 2021

Published online: 24 August 2021

(c) The Author(s) 2021

\section{Conquering nightmares on the phone: one-session counseling using imagery rehearsal therapy}

\author{
Katharina Lüth ${ }^{1,2}$. Judith Schmitt ${ }^{3} \cdot$ Michael Schredl' \\ ${ }^{1}$ Central Institute of Mental Health, Medical Faculty Mannheim/Heidelberg University, Mannheim, \\ Germany \\ ${ }^{2}$ Institut für Kognitionswissenschaft, Universität Osnabrück, Osnabrück, Germany \\ ${ }^{3}$ Abteilung für Schlafmedizin, Theresienkrankenhaus und St. Hedwig-Klinik GmbH, Mannheim, Germany
}

\title{
Abstract
}

Background: Since people with nightmares rarely seek help, low-threshold interventions and self-help methods are needed. Among different treatment approaches for nightmares, imagery rehearsal therapy (IRT) is the method of choice. Objective: In the current study, the authors tested whether IRT is also effective when applied in a short version, within the scope of a single session of telephone counseling. Methods: The nightmare frequency and nightmare distress of 28 participants was investigated before and 8 weeks after one session of telephone counseling. The 30minute session included information on nightmare etiology as well as a short version of IRT. The session was followed by an 8-week period of self-practice. Participants were either part of a student group or part of a group of patients from a sleep laboratory. Within-group and between-group differences were assessed. There was no control group.

Results: The intervention significantly reduced nightmare frequency and nightmare distress in the total sample and in both samples individually analyzed. Effect sizes were very high compared to those of waiting-list control groups of similar studies.

Conclusion: We were able to show that a one-session intervention can be enough to achieve significant relief from nightmares. As nightmares are underdiagnosed and undertreated, this approach might help to provide a low-threshold intervention for nightmare sufferers.

\section{Keywords}

Parasomnias · Dreams · Distress · Treatment adherence and compliance · Sleep wake disorders

About 3 to $8 \%$ of the population experience frequent nightmares, typically defined as one or more nightmares per week [1]. The International Classification of Sleep Disorders (version 3; ICSD3) defines nightmares as extended and extremely dysphoric dreams that are well remembered and contain life-threatening events or threats to security and/or physical integrity [2]. Nightmares are differentiated into posttraumatic and idiopathic nightmares. Posttraumatic nightmares refer to traumatic events and are typically a symptom of posttraumatic stress disorder (PTSD) [3]. In the etiology of idiopathic nightmares (not related to specific trau- matic events), a disposition-stress model is commonly used [4]. The tendency to experience nightmares can be heightened by genetic dispositions [5] as well as by the personality traits thin boundaries [6] and neuroticism [7]. Besides stress [8], several classes of medication can trigger nightmares, e.g., antidepressants, hypnotics, benzodiazepines, and dopamine agonists [9].

Several studies have indicated that nightmares are highly underdiagnosed and undertreated $[10,11]$. Only 11.1 up to $37.8 \%$ of the participants who experience clinically significant nightmares reported having sought professional help 


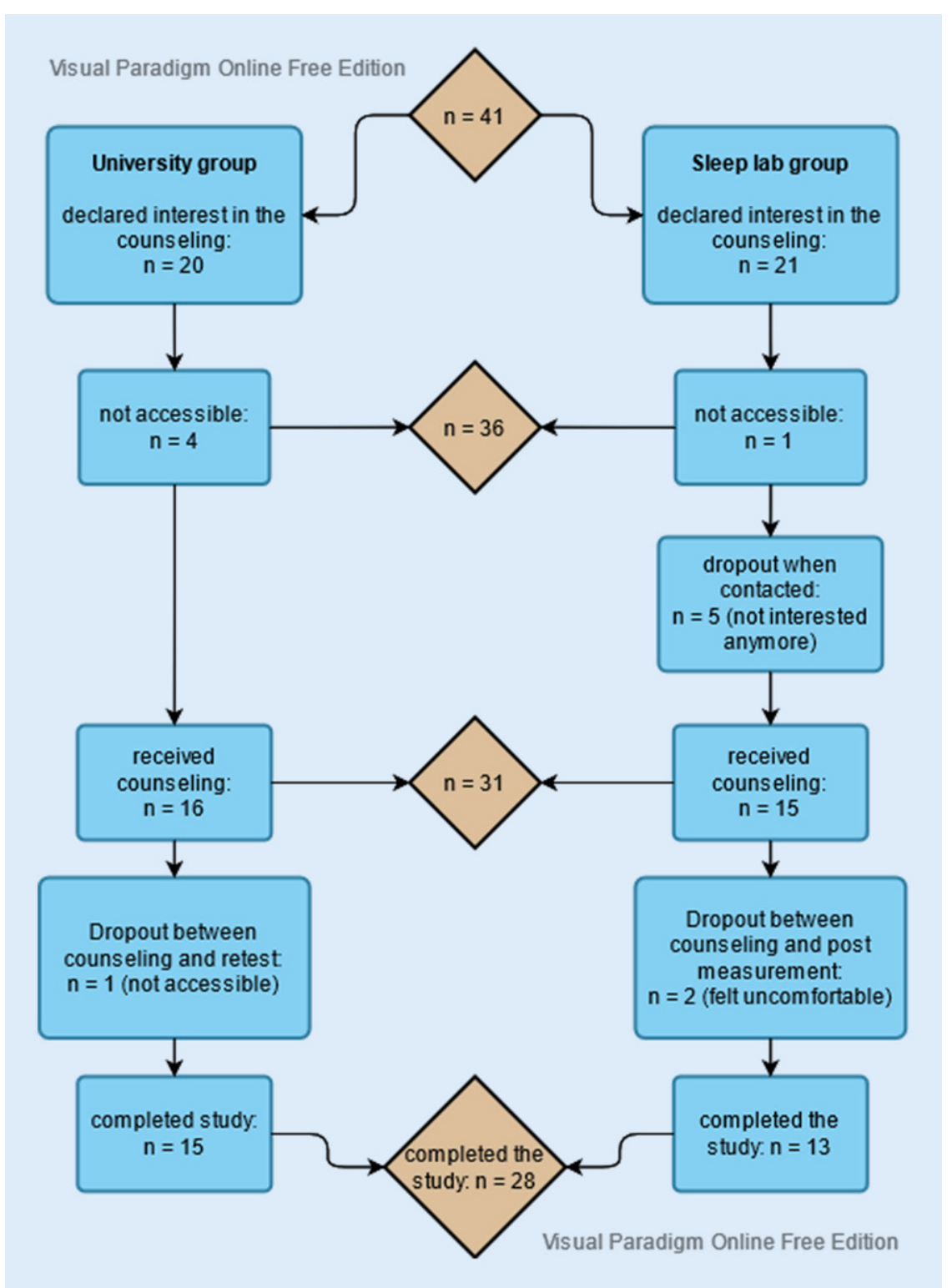

Fig. 1 A Flowchart displaying participants and dropouts (reasons in brackets). Two participants of the sleep lab group felt uncomfortable talking about private topics on the phone and therefore decided to cease participation

[10-13]. However, previous studies indicated that when directly offered help, 15.5 up to $46.8 \%$ of people with frequent nightmares (once a week or more often) expressed their interest in telephone counseling covering information

\section{Abbreviations}

CPAP Continuous positive airway pressure

ICSD-3 International Classification of Sleep Disorders-version 3

IRT Imagery rehearsal therapy

OSA Obstructive sleep apnea

PTSD Posttraumatic stress disorder on the etiology and treatment of nightmares $[13,14]$. Therefore, low-threshold interventions are urgently needed.

Among treatments for nightmares, which include pharmacological and psychotherapeutic approaches, imagery rehearsal therapy (IRT) is the most frequently recommended technique [15], because it is supported by the best empirical evidence $[16,17]$. In IRT, the course of a nightmare is rescripted, i.e., a dream report is rewritten into a pleasant dream during wakefulness [18]. Subsequently, the rewritten dream is visualized daily for 5-10 min for 2 weeks.

IRT has been delivered in various lengths, ranging from single sessions [19] to four [18] or eight therapy sessions [20]. Besides face-to-face interventions, modern formats also exist, e.g., internetbased IRT has yielded positive results [21]. In a very recent study, a self-help format combined with telephone support also led to significant nightmare reduction [22].

The present study investigates the effect of a single session of IRT-based telephone counseling on nightmare frequency and nightmare distress in participants who suffer from nightmares. The authors hypothesized that one telephone session followed by self-practice would reduce nightmare frequency and nightmare distress.

\section{Methods}

\section{Recruitment}

Participants were recruited in the sleep center of the Theresienkrankenhaus, Mannheim, Germany, and at Osnabrück University, Germany. These two groups (sleep lab group and university group) were screened differently: participants from the sleep lab group were examined with a nightmare questionnaire about nightmare frequency, distress, and topics, which was developed in a previous study by Schredl, Dehmlow, and Schmitt [13]. In that questionnaire, the participants were offered telephone counseling which would cover possible causes and a treatment option ("Within a study we have the possibility to offer you, if you wish, a telephone consultation [about $30 \mathrm{~min}$ ] on the most important facts concerning nightmares. The presented technique is very easy to apply and very effective. In short, it is about inventing a new dream ending while awake and practicing it in the imagination. Are you interested in using this offer for yourself?"). If the participants declared interest in taking part, they were contacted via telephone. Participants of the university group were recruited via email lists. Participants who responded and declared interest were contacted via telephone. We did not provide a definition of nightmares to 


\begin{tabular}{|c|c|c|c|c|c|c|c|}
\hline \multirow[t]{2}{*}{ Sample } & \multicolumn{3}{|c|}{$\begin{array}{l}\text { Changes in nightmare frequency from baseline to } \\
\text { retest }\end{array}$} & \multirow{2}{*}{$\begin{array}{l}\text { Mean } \pm \text { SD of } \\
\text { baseline night- } \\
\text { mare frequency }\end{array}$} & \multirow{2}{*}{$\begin{array}{l}\text { Mean } \pm \text { SD } \\
\text { base- } \\
\text { line-retest } \\
\text { difference }\end{array}$} & \multirow{2}{*}{$\begin{array}{l}\text { Wilcoxon } \\
\text { signed-rank } \\
\text { test }\end{array}$} & \multirow{2}{*}{$\begin{array}{l}\text { Effect } \\
\text { size (Co- } \\
\text { hen's d) }\end{array}$} \\
\hline & Decreased & Unchanged & Increased & & & & \\
\hline $\begin{array}{l}\text { Sleep lab group } \\
(n=13)\end{array}$ & 10 & 3 & 0 & $6.69 \pm 0.95$ & $-2.46 \pm 1.90$ & $\begin{array}{l}p=0.002 \\
Z=-2.82\end{array}$ & $d=2.51$ \\
\hline $\begin{array}{l}\text { University group } \\
(n=15)\end{array}$ & 8 & 5 & 2 & $7.13 \pm 0.99$ & $-0.93 \pm 1.58$ & $\begin{array}{l}p=0.016 \\
Z=-2.14\end{array}$ & $d=1.33$ \\
\hline $\begin{array}{l}\text { Total } \\
(n=28)\end{array}$ & 18 & 8 & 2 & $6.93 \pm 0.98$ & $-1.64 \pm 1.87$ & $\begin{array}{l}p<0.001 \\
Z=-3.65\end{array}$ & $d=1.91$ \\
\hline
\end{tabular}

\begin{tabular}{|l|l|l|l|l|l|l|}
\hline Table 2 & Nightmare distress before and after the intervention \\
\hline \multirow{2}{*}{ Time } & Sample & \multicolumn{2}{|l|}{ Nightmare distress } \\
\cline { 3 - 8 } & None & Little & Moderate & Strong & Very strong \\
\hline Baseline & $\begin{array}{l}\text { Sleep lab group } \\
(n=13)\end{array}$ & 2 & 6 & 2 & 0 & 3 \\
\cline { 2 - 7 } & $\begin{array}{l}\text { University group } \\
(n=15)\end{array}$ & 0 & 4 & 10 & 1 & 0 \\
\cline { 2 - 8 } & $\begin{array}{l}\text { Total } \\
(n=28)\end{array}$ & 2 & 10 & 12 & 1 & 3 \\
\hline 8 weeks & $\begin{array}{l}\text { Sleep lab group } \\
(n=13)\end{array}$ & 8 & 3 & 1 & 1 & 0 \\
\cline { 2 - 7 } & $\begin{array}{l}\text { University group } \\
(n=14)\end{array}$ & 2 & 8 & 3 & 0 & 1 \\
\cline { 2 - 7 } & $\begin{array}{l}\text { Total } \\
(n=27)\end{array}$ & 10 & 11 & 4 & 1 & 1 \\
\hline
\end{tabular}

persons interested in the study and no diagnostic criterion was applied. There were no exclusion criteria, in order to allow everyone who was interested in consulting to also participate, regardless of how often their nightmares occurred. Thus, the only inclusion criterion was that people were interested in getting help for their nightmares.

\section{Participants}

A total of 41 participants were eligible for the study, of whom five could not be contacted. The remaining 36 individuals were included in the study. Eight participants dropped out during the study, which resulted in a dropout rate of $22.2 \%$. For dropout reasons, see $\bullet$ Fig. 1.

In total, 28 participants completed the study. The sleep lab group consisted of 13 participants ( 8 males, 5 females, mean age $58.5 \pm 11.9$ years). The current sleep lab sample is part of a bigger sample of another study [23]. Comorbidities are known for the sleep lab group: all participants from this group were diagnosed with sleep-related breathing disorders and-if necessary-received treatment accordingly (continuous positive airway pressure, CPAP; initiation 3-4 months prior to the nightmare counseling); other comorbidities mainly included diabetes, hypertension, thyroid diseases, heart diseases, asthma, lung diseases, and mental disorders (which were not included in the analysis as the interest lay in the results of the pre-post test and the sample of 13 participants was too small to investigate the influence of comorbidities on therapeutic success). No information was available regarding the type of nightmares (posttraumatic or idiopathic), but it was known that none of the participants had a comorbid posttraumatic stress disorder.

The university group consisted of 15 participants (2 males, 13 females, mean age $27.3 \pm 6.2$ years). No information regarding comorbidities or the type of nightmares (posttraumatic or idiopathic) was available for the university sample.

The study was approved by Ethics Committee II at Heidelberg University (Medical Faculty Mannheim). All participants signed informed consent.

\section{Procedure}

\section{Counseling call}

The 28 participants received two telephone calls 8 weeks apart. In the first call (counseling call, roughly $30 \mathrm{~min}$ ), nightmare frequency was assessed using an eight-point scale ( $1=$ never, $2=$ less than once a year, $3=$ about once a year, $4=$ about 2-4 times a year, $5=$ about once a month, $6=2-3$ times a month, $7=$ about once a week, or $8=$ several times a week). The retest reliability (4-week interval) of this scale was high $(r=0.75)$ [24]. Nightmare distress was assessed using a five-point scale ( $1=$ no distress, $2=$ a little, $3=$ moderate, $4=$ strong, or $5=$ very strong distress). The retest reliability of the scale (2-week interval) was $r=0.673$ [25]. We also asked which themes were most prevalent and whether participants had ever done anything about their nightmares. The questions were followed by psychoeducation about nightmare etiology and an introduction to the basic principles of IRT. The execution of IRT included reporting a nightmare and rescripting its content. The rescription of the nightmare was performed interactively: participants were asked to find a possibility to change the dream script ("Can you think of anything you could do in that situation?"). If the participant's idea included avoidance behavior (e.g., running away in the dream scene), the participant 


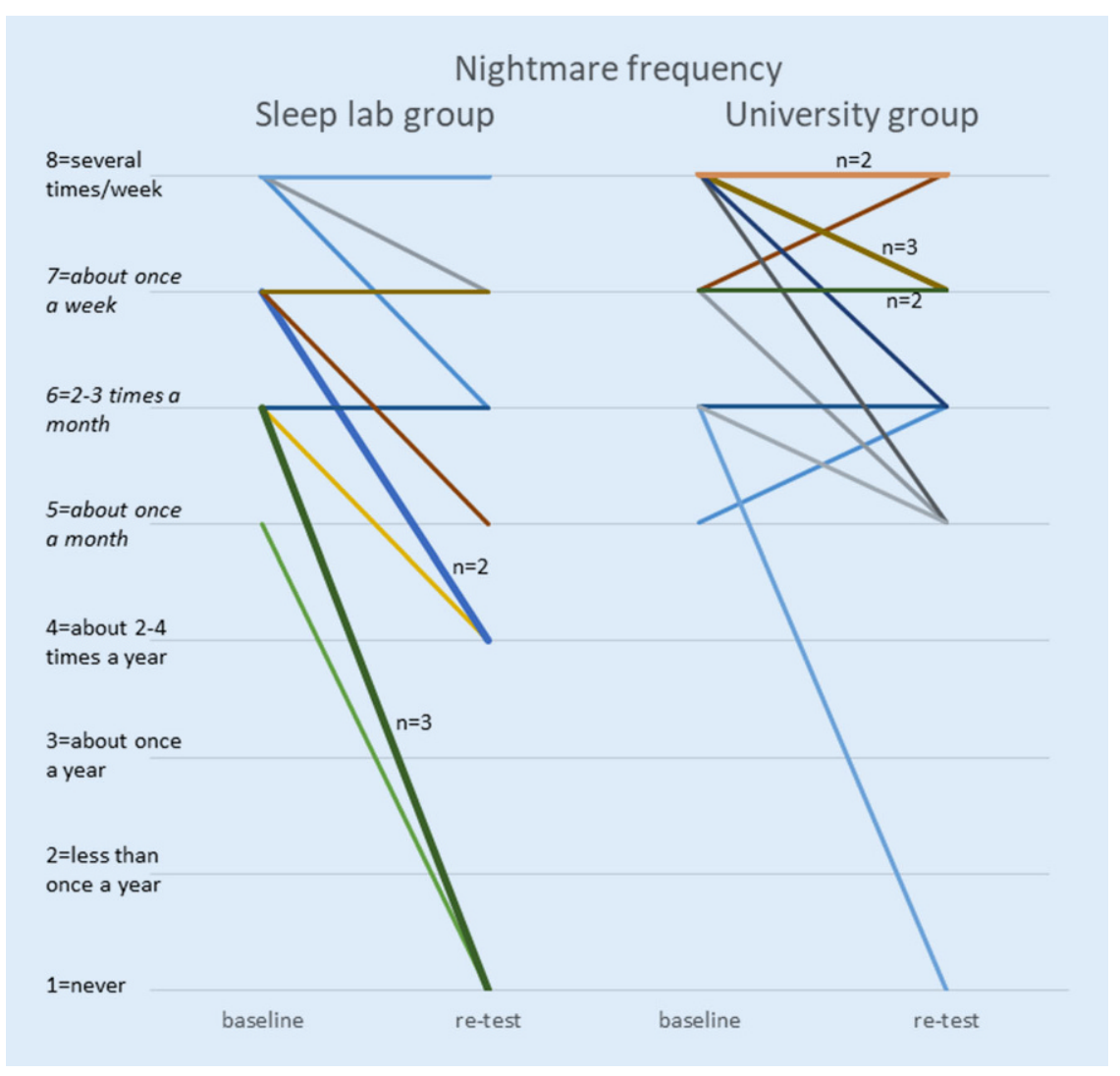

Fig. $2 \Delta$ Nightmare frequency before and after the intervention. Every line represents one subject unless stated differently. Thicker lines represent more participants. Sleep lab group: $n=13$, university group: $n=15$

was asked to think about an alternative, because active solution-oriented behavior, such as asking for help, is useful [26]. If the participant had no idea, the counselor made suggestions and an active solution strategy was developed together. Finally, the participants were advised to practice each day for 2 weeks, always with the same dream as had been rescripted during the telephone session. Additionally, but voluntarily, for the remaining 6 weeks, participants could continue with rescripting more nightmares and practicing in the same way as in the first 2 weeks of the self-practice phase. Practicing with the first dream for 2 weeks was mandatory, while continuing to practice was voluntary ("After 2 weeks you can use the same exercise with another dream and continue with another dream every 2 weeks until we talk again"). The participants were offered the opportunity to call the counselor during the 8-week interval between the two telephone conversations if additional advice was desired.

\section{Retest telephone call}

During the second call, the participants were asked about their nightmare frequency and nightmare distress again, using the same scales as in the first call. It was also assessed how the participants perceived the IRT technique ("What were your experiences with the technique?"), and, if necessary, what difficulties they were facing. They were also asked how, how often, and with how many dreams they had used the technique, and whether they perceived the technique to be helpful. Lastly, participants were asked about changes in waking life. All these items were answered freely.

\section{Statistical analyses}

Data were analyzed using IBM SPSS Statistics version 26 (IBM Corp., Armonk, NY, USA). Wilcoxon signed-rank tests were applied to compare nightmare frequency and nightmare distress before and after the 8-week interval. Although we used statistical tests for ordinal data, we report the mean of pre-post differences for de- scriptive purposes. Differences in the prepost change scores between groups were assessed with Mann-Whitney $\mathrm{U}$ tests. To calculate effect sizes (Cohen's d) for ordinal data, we used the Z-values and a formula provided by Fritz et al. [27] to calculate $r$ from $Z$ in non-parametrical tests and, in a second step, transform $r$ to $d$. Effect sizes were interpreted as small if $d=0.2$, medium if $d=0.5$, and large if $d \geq 0.8$, according to Cohen [28]. Correlations were calculated using the Spearman's rank-order correlation, $\mathrm{r}_{\mathrm{s}}$.

\section{Results}

\section{Nightmare frequency}

At baseline, 10 of 28 participants reported having nightmares several times a week, 8 reported nightmares about once a week, 8 had nightmares about 2-3 times a month, and 2 participants reported monthly nightmares. After the intervention, nightmare frequency was reduced in $64 \%$ of participants. The overall nightmare frequency posttreatment was significantly lower compared to baseline $(p<0.001, \mathrm{Z}=-3.65, \mathrm{~d}=1.91)$. Analyzed individually, both groups improved significantly (•Table 1 ). Of those participants who reported nightmares at least once a week at baseline $(n=18), 61 \%(n=11)$ had a reduced nightmare frequency in the retest $(p=0.002, Z=-2.86, d=1.83$, mean pre-post difference $=-1.11 \pm 1.23$ categories). Difference between samples: there were no significant baseline differences between the groups regarding nightmare frequency (MannWhitney $U=71.50, Z=-1.26, p=0.209$, $d=0.49$ ). The sleep lab sample profited significantly more than the university sample (Man-Whitney $U=52.00, Z=-2.14$, $p=0.0326, \mathrm{~d}=0.88$ ). D Figure 2 shows the nightmare frequency of each participant before and after the intervention.

\section{Nightmare distress}

At baseline, nightmare distress was perceived as little to moderate by the majority of participants (79\%, - Table 2). After the intervention, nightmare distress was reduced in $63 \%$ of participants and the majority $(78 \%)$ reported no to little distress. 
Table 3 Pre-post changes in nightmare distress

\begin{tabular}{|c|c|c|c|c|c|c|c|}
\hline \multirow[t]{2}{*}{ Sample } & \multicolumn{3}{|c|}{$\begin{array}{l}\text { Change in nightmare distress from baseline to } \\
\text { retest }\end{array}$} & \multirow{2}{*}{$\begin{array}{l}\text { Mean } \pm \text { SD of } \\
\text { baseline night- } \\
\text { mare distress }\end{array}$} & \multirow{2}{*}{$\begin{array}{l}\text { Mean } \pm \text { SD of dif- } \\
\text { ference baseline } \\
\text { and retest }\end{array}$} & \multirow{2}{*}{$\begin{array}{l}\text { Wilcoxon } \\
\text { signed-rank } \\
\text { test }\end{array}$} & \multirow[t]{2}{*}{$\begin{array}{l}\text { Effect size } \\
\text { (Cohen's d) }\end{array}$} \\
\hline & Decreased & Unchanged & Increased & & & & \\
\hline $\begin{array}{l}\text { Sleep lab group } \\
(n=13)\end{array}$ & 9 & 4 & 0 & $2.69 \pm 1.44$ & $-1.08 \pm 1.12$ & $\begin{array}{l}p=0.003 \\
Z=-2.75\end{array}$ & $d=2.37$ \\
\hline $\begin{array}{l}\text { University group } \\
(n=14)^{\mathrm{a}}\end{array}$ & 8 & 5 & 1 & $\begin{array}{l}2.80 \pm 0.56 \\
(n=15)\end{array}$ & $-0.57 \pm 0.76$ & $\begin{array}{l}p=0.010 \\
Z=-2.31\end{array}$ & $d=1.57$ \\
\hline $\begin{array}{l}\text { Total } \\
(n=27)\end{array}$ & 17 & 9 & 1 & $\begin{array}{l}2.75 \pm 1.04 \\
(n=28)\end{array}$ & $-0.81 \pm 0.96$ & $\begin{array}{l}p<0.001 \\
Z=-3.60\end{array}$ & $d=1.92$ \\
\hline
\end{tabular}

Columns 2-4 display the numbers of participants whose nightmare distress decreased, remained constant, or increased after the intervention

SD standard deviation

${ }^{\mathrm{a}}$ One of 15 participants gave no answer in the retest

\begin{tabular}{|c|c|c|c|c|c|}
\hline Timepoint & Group & $\begin{array}{l}\text { Not help- } \\
\text { ful }\end{array}$ & $\begin{array}{l}\text { Somewhat } \\
\text { helpful }\end{array}$ & Helpful & $\begin{array}{l}\text { Very help- } \\
\text { ful }\end{array}$ \\
\hline \multirow{3}{*}{$\begin{array}{l}\text { Evaluation } 1 \\
\text { (end of } \\
\text { phone call 1) }\end{array}$} & $\begin{array}{l}\text { Sleep lab group } \\
(n=13)\end{array}$ & 0 & 0 & 6 & 7 \\
\hline & $\begin{array}{l}\text { University group } \\
(n=15)\end{array}$ & 0 & 2 & 5 & 8 \\
\hline & $\begin{array}{l}\text { Total } \\
(n=28)\end{array}$ & 0 & 2 & 11 & 15 \\
\hline \multirow{3}{*}{$\begin{array}{l}\text { Evaluation } 2 \\
\text { (end of } \\
\text { phone call 2) }\end{array}$} & $\begin{array}{l}\text { Sleep lab group } \\
(n=13)\end{array}$ & 0 & 1 & 3 & 9 \\
\hline & $\begin{array}{l}\text { University group } \\
(n=15)\end{array}$ & 0 & 0 & 7 & 8 \\
\hline & $\begin{array}{l}\text { Total } \\
(n=28)\end{array}$ & 0 & 1 & 10 & 17 \\
\hline
\end{tabular}

Overall posttreatment nightmare distress was significantly lower compared to baseline $(p<0.001, Z=-3.60, d=1.92)$. Both samples analyzed individually improved significantly (- Table 3). There was no significant difference in nightmare distress between the samples at baseline (Man$n$-Whitney $\mathrm{U}=75.00, p=0.268, \mathrm{Z}=-1.11$, $\mathrm{d}=0.43$ ) and no significant difference in the change scores between groups (Man$n-$ Whitney $\mathrm{U}=70.00, p=0.269, \mathrm{Z}=-1.11$, $d=0.44$ ).

\section{Subjective experiences with IRT}

\section{Negative experiences}

Two participants perceived it as frightening to imagine the rescripted dream because it still contained the distressing situation of the nightmare at the beginning. One of these subjects described that she was able to imagine the rescripted part with many positive images, but the emotions were still affected by the old version of the nightmare. Another person reported that the imagination did not work very well. No other negative experience with the method was reported.

\section{Positive experiences}

Many participants $(n=19)$ reported positive experiences. In this section, all feedback that was mentioned more than once is reported. Immediate progress, e.g., "The dreams completely disappeared as if they were switched off," was reported by 3 participants. Some participants highlighted that they liked the method $(n=7)$, e.g., because it is easy to apply $(n=2)$ or because they liked the way of working $(n=3$; "It was good to work creatively, to invest in it, and to take this challenge."). Another 3 participants were happy to have a method to use in the future if nightmares reoccurred, e.g., "Having learned the technique makes me feel safe." Two participants also reported a eureka moment when they learned that something can be done about the nightmares, e.g., "I wouldn't have come up with the idea that I can influence my dreams." In a multiple-choice question evaluating the counseling, 27 of 28 participants evaluated the counseling as helpful or very helpful (• Table 4).

\section{Amount and kind of practice}

We asked how often the participants practiced, and the answers varied from having practiced for only a few days to having practiced for 8 weeks. Since many participants did not remember exactly when they had stopped practicing, not all answers are listed here, but the general impression is that the majority of participants practiced regularly for about 2-4 weeks before it gradually became less and less. Whereas 12 participants practiced IRT only with the dream that was rescripted during the telephone session, 6 participants applied IRT to a second dream, and 6 participants reported having rescripted more than two dreams. Two participants replied "several" but gave no number, one participant did not remember how many dreams were rescripted, and one gave no answer. The number of rescripted dreams weakly negatively and marginally significantly correlated with the pre-post decrease in nightmare frequency $\left(r_{s .}=-0.38\right.$, $p=0.065, n=24)$, that is, the more dreams were rescripted, the smaller was the decrease in nightmare frequency. There was no correlation between the number of rescripted dreams and the decrease in nightmare distress $\left(r_{s .}=-0.19, p=0.398, n=23\right)$.

Even though the advice was to write down the rescripted dream, 5 participants reported having rescripted only in their thoughts, 12 wrote it down, and 11 gave no answer. An additional coping strategy was applied by 3 participants for their 
nightmares: they improved their sleep hygiene by turning off their mobile phone earlier, practicing meditation, or by listening to a guided imagination to facilitate falling asleep. Nobody made use of the offer to contact the experimenter during the study period in case of questions or problems.

\section{Effect of the intervention on waking life}

There were no reports of negative effects of the intervention on waking lives. Changes in waking life were reported by 16 participants: neutral comments addressed having more conversations about dreams $(n=1)$, more conversations about problems $(n=1)$, thinking more about dreams $(n=1)$, and more rational thinking $(n=1)$. Several participants reported positive changes such as good mood ( $n=4)$, e.g., "I begin my day more relaxed. I have less negative feelings while waking up," decreased fear in the dark $(n=1)$, more empathy $(n=2)$, less thoughts about nightmares $(n=2)$, a feeling that nightmares become shorter $(n=1)$, less doubts $(n=1)$, and beneficial insights into emotions ( $n=1$; "I have learned to find out what I am afraid of, I can now identify my problems in waking life."). No changes in waking life were reported by 12 participants.

\section{Seeking help for nightmares}

In this section, all the answers given by more than one person to the question "Have you ever done anything about your nightmares?" are reported. Nobody reported to have ever sought professional help. Four participants (sleep lab group) specified reasons for refraining from seeking help and reported a fear of being discriminated, e.g., "IfI told my doctors, they would think I am insane," or "My family and friends just shook their heads when I told them about my nightmares." One of these four participants also reported: "You [the counselor] are the first one who talks to me about my nightmares." Only elderly people (sleep laboratory group) reported these fears about the reactions of others. Seven participants (six of the university group and one from the sleep lab group) reported that they talk to friends, family members, or flat mates about their nightmares. Two participants of the university group specified that they did not look for help because they did not know that nightmares can be a disorder and treatable, e.g., "I did not know that this is pathological," and "I have always seen dreams as something irrevocable."

\section{Discussion}

\section{Effectiveness}

The present study indicated that a one-session telephone counseling including a brief version of IRT can reduce nightmare frequency and distress significantly in people who suffer from nightmares. The dropout rate in the present study $(22.2 \%)$ is low compared to other studies using psychological treatments for nightmares, where dropout rates range from 23.4 to $51.9 \%$ [16]. Reported consequences of practicing IRT were almost exclusively positive and adverse effects were rare. Only 2 of 28 participants experienced the technique as disturbing but still did not contact the experimenter for help. As nightmare sufferers might have problems with seeking help [10-12], it might be helpful to regularly check on participants via email or social media.

The finding that a single-session intervention can help people with nightmares has been reported previously [19, 29]. Recently, Lancee et al. [22] also showed that IRT is effective with little time investment: in their study, IRT was delivered within three 15-minute telephone sessions combined with self-help. Thus, a very short treatment is enough to achieve effects, only a few people need a longer therapy.

The current effect sizes (Cohen's $d=1.91$ for nightmare frequency and $d=1.92$ for nightmare distress) are very large, compared to overall medium to large effect sizes reported in meta-analyses [16, 17]. Based on the responses of the participants, the authors assume that there was a strong general effect of the intervention; for the majority of participants, it was the first time that a professional had addressed their problem, offered expertise regarding nightmare etiology, and outlined a simple procedure to cope with nightmares, i.e., introducing the idea that nightmare frequency can be reduced. As elderly per- sons have less access to resources like the internet (nightmare-related websites) - in addition to talking about dreams less often with others compared to younger persons [25] - it might be plausible that this general effect might be more pronounced in the sleep lab group. To test this hypothesis, a dismantling study looking for the effect of tailored psychoeducation without intervention on nightmare frequency would be of great interest.

The more dreams were processed, the less the nightmare frequency decreased. It could therefore be that those who had less success in the end tried it longer than those who had a large decrease in nightmare frequency, i.e., for those for whom it worked well (large decrease in nightmare frequency), it also worked quickly (and it was not necessary to work on more dreams).

Unfortunately, no control group was implemented in the present study. However, the overall effect size is much larger compared to waiting-list control groups of other IRT studies. For instance, Krakow et al. found an effect size of $d=0.20$ in a waiting-list control group and $d=1.24$ in the IRT group (measure: number of nights with nightmares per week) [30]. In a recent study by Lancee et al. testing telephone-guided IRT, the waiting-list control group had an effect size of $d=0.08$ for log-transformed nightmare frequency (where the IRT group had an effect size of $d=1.11$ ). The waiting-list group's effect size for nightmare distress was $d=1.12$, while the IRT group had an effect size of $d=1.87$ [22]. Taking into account the effect sizes of the control groups of similar studies, it can be strongly assumed that the current method had an effect although there was no control group. Whether these high effect sizes at the end of the 8-week study period can be maintained is an important question for future research. Other research showed stable effects in up to 30 months of follow-up [31].

\section{Methodological discussion/ limitations}

The current study has some methodological limitations. Firstly, as discussed above, one major limitation of the current study is the lack of a control group, i.e., this 
study cannot clearly determine the effective component.

The sleep lab group consisted of patients with obstructive sleep apnea (OSA). However, CPAP treatment-if necessary - was already initiated 3-4 months prior to the baseline measurement of the telephone counseling [23]. Thus, the current effects in this group could not be explained by the previously reported positive effect of CPAP treatment on nightmare frequency [32].

Besides, we did not elicit other outcomes such as sleep quality or daytime mood. Improved sleep quality and daytime mood after IRT have been found in previous research [33], whereas others did not find these improvements [21]. Also, as the telephone sessions were not recorded, it was not possible to check whether the interviewer strictly adhered to the protocol. This would be very important if several interviewers performed the telephone session, although all interviews were carried out by the first author in the current study.

For the retest, we asked the participants to estimate their current nightmare frequency over the last 8 weeks. As such, the options "less than once a year," "about once a year," and "about 2-4 times a year" did not make sense, and those participants who had had one nightmare in the past 8 weeks might have answered "2-4 times a year" or "about once a month." Using the eight-point scale increased error variance, but these measurement issues only had a minimal effect on the pre-post comparisons (given the major changes in nightmare frequency for most of the participants).

Unfortunately, treatment adherence was not systematically elicited, as the participants were only asked in a general way about whether they were practicing or not. An interesting question for future research would be whether there is a dose-dependent relationship between practicing at home and nightmare frequency.

Lastly, the participants' evaluation of the counseling might be biased, as the interviewer herself elicited the evaluation (social expectancy bias). A post-study questionnaire sent to the participants after the retest would be necessary to corroborate this.

\section{Conclusion}

This study showed that a single telephone session can decrease nightmare frequency considerably. None of the 28 participants, of whom 18 had nightmares at least once a week at baseline, had sought help before being offered participation in this study. This confirms the need for low-threshold methods and self-help approaches to simplify access to treatment [4]. One option would be to educate health care providers to directly ask patients specifically about nightmares $[13,17]$. This study and a previous study [13] indicate that reaching out to patients in sleep laboratories can be very effective. Therefore, a pending task is to communicate this treatment option to health care providers and the general population, including the people with nightmares. Because of the simplicity and the effectiveness of this method, we stress the idea put forward by many dream researchers $[4,11,13]$ that such easily accessible offers for nightmare treatment should be implemented in our health care system.

\section{Practical conclusions for sleep medicine}

- The presented technique can be explained using three steps (write down a nightmare, rewrite the nightmare, and practice the new story).

- People with nightmares rarely ask for help: some people fear being discriminated against if they told their doctors or families about their nightmares. Also, there is a lack of knowledge that nightmares are a treatable condition [12].

- In case of sleep-disturbed patients, practitioners should directly ask for nightmares.

\section{Corresponding address}

Katharina Lüth, M.Sc.

Institut für Kognitionswissenschaft, Universität Osnabrück

Osnabrück, Germany

katharina.lueth@uni-osnabrueck.de

Funding. Open Access funding enabled and organized by Projekt DEAL.

\section{Declarations}

Conflict of interest. K. Lüth, J.Schmitt, and M. SchredI declare that they have no competing interests.

All procedures performed in studies involving human participants were in accordance with the ethical standards of the institutional and/or national research committee (Ethics Committee II at Heidelberg University, Medical Faculty Mannheim) and with the 1964 Helsinki declaration and its later amendments or comparable ethical standards. Informed consent was obtained from all individual participants in the study.

Open Access. This article is licensed under a Creative Commons Attribution 4.0 International License, which permits use, sharing, adaptation, distribution and reproduction in any medium or format, as long as you give appropriate credit to the original author(s) and the source, provide a link to the Creative Commons licence, and indicate if changes were made. The images or other third party material in this article are included in the article's Creative Commons licence, unless indicated otherwise in a credit line to the material. If material is not included in the article's Creative Commons licence and your intended use is not permitted by statutory regulation or exceeds the permitted use, you will need to obtain permission directly from the copyright holder. To view a copy of this licence, visit http://creativecommons.org/licenses/by/4.0/.

\section{References}

1. Schredl M (2010) Nightmare frequency and nightmare topics in a representative German sample. Eur Arch Psychiatry Clin Neurosci 260:565-570. https://doi.org/10.1007/s00406 010-0112-3

2. Mayer G, Rodenbeck A, Geisler P, Schulz H (2015) Internationale Klassifikation der Schlafstörungen: Übersicht über die Änderungen in der ICSD. Somnologie 19:116-125. https://doi.org/10. 1007/s11818-015-0006-8

3. American Psychiatric Association (2013) Diagnostic and statistical manual of mental disorders: DSM-5. American Psychiatric Association, Washington, $D C$

4. Gieselmann A, Ait Aoudia M, Carr M, Germain A, Gorzka R, Holzinger $B$, Kleim B, Krakow $B$, Kunze $A E$, Lancee J, Nadorff MR, Nielsen $T$, Riemann D, Sandahl H, Schlarb AA, Schmid C, Schredl M, Spoormaker VI, Steil R, van Schagen AM, Wittmann L, Zschoche M, Pietrowsky R (2019) Aetiology and treatment of nightmare disorder: state of the art and future perspectives. J Sleep Res. https://doi.org/10.1111/jsr.12820

5. Hublin C, Kaprio J, Partinen M, Koskenvuo M (1999) Nightmares: familial aggregation and association with psychiatric disorders in a nationwide twin cohort. Am J Med Genet Neuropsychiatr Genet 88:329-336. https://doi.org/10.1002/(SICI)10968628(19990820)88:4(329::AID-AJMG8)3.0.CO;2-E

6. Schredl M, Kleinferchner P, Gell T (1996) Dreaming and personality: thick vs. thin boundaries. Dreaming 6:219-223. https://doi.org/10.1037/ h0094456

7. Schredl M, Goeritz AS (2019) Nightmare frequency and nightmare distress: Socio-demographic and personality factors. Sleep Sci 12:178-184. https:// doi.org/10.5935/1984-0063.20190080 
8. Köthe M, Pietrowsky R (2001) Behavioral effects of nightmares and their correlations to personality patterns. Dreaming 11:43-52. https://doi.org/10. 1023/A:1009468517557

9. Pagel JF, Helfter P (2003) Drug induced nightmares - an etiology based review. Hum Psychopharmacol 18:59-67. https://doi.org/10.1002/ hup. 465

10. Schredl M (2013) Seeking professional help for nightmares: a representative study. Eur J Psychiatry 27:259-264. https://doi.org/10.4321/ S0213-61632013000400004

11. Thünker J, Norpoth $M$, von Aspern $M$, Özcan $T$, Pietrowky R (2014) Nightmares: knowledge and attitudes in health care providers and nightmare sufferers. J Public Health Epidemiol 6:223-228. https://doi.org/10.5897/jphe2013.0565

12. Nadorff MR, Nadorff DK, Germain A (2015) Nightmares: under-reported, undetected, and therefore untreated. JClin Sleep Med 11:747-750

13. Schredl M, Dehmlow L, Schmitt J (2016) Interest in information about nightmares in patients with sleep disorders. J Clin Sleep Med 12:973-977. https://doi.org/10.5664/jcsm.5928

14. Schredl M, Lüth K, Schmitt J (2020) Interest in telephone nightmare counselling in patients with sleep-related breathing disorders. Somnologie 24:2-10. https://doi.org/10.1007/s11818-02000254-9

15. Aurora RN, Zak RS, Auerbach SH, Casey KR, Chowdhuri S, Karippot A, Maganti RK, Ramar K, Kristo DA, Bista SR, Lamm Cl, Morgenthaler TI, Tracy SL (2010) Best practice guide for the treatment of nightmare disorder in adults. J Clin Sleep Med 6:389-401

16. Augedal AW, Hansen KS, Kronhaug CR, Harvey AG, Pallesen S (2013) Randomized controlled trials of psychological and pharmacological treatments for nightmares: a meta-analysis. Sleep Med Rev 17:143-152. https://doi.org/10.1016/j.smrv.2012. 06.001

17. Hansen K, Höfling V, Kröner-Borowik T, Stangier U, Steil R (2013) Efficacy of psychological interventions aiming to reduce chronic nightmares: a metaanalysis. Clin Psychol Rev 33:146-155. https://doi. org/10.1016/j.cpr.2012.10.012

18. Krakow B, Zadra A (2006) Clinical management of chronic nightmares: Imagery rehearsal therapy. Behav Sleep Med 4:45-70. https://doi.org/10. 1207/s15402010bsm0401_4

19. Germain A, Nielsen T (2003) Impact of imagery rehearsal treatment on distressing dreams, psychological distress, and sleep parameters in nightmare patients. Behav Sleep Med 1:140-154. https://doi.org/10.1207/S15402010BSM0103_2

20. Thünker J, Pietrowsky R (2012) Effectiveness of a manualized imagery rehearsal therapy for patients suffering from nightmare disorders with and without a comorbidity of depression or PTSD. Behav Res Ther 50:558-564. https://doi.org/10. 1016/j.brat.2012.05.006

21. Gieselmann A, Böckermann $M$, Sorbi $M$, Pietrowsky R (2017) The effects of an Internet-based imagery rehearsal intervention: a randomized controlled trial. Psychother Psychosom 86:231-240. https://doi.org/10.1159/ 000470846

22. Lancee J, Effting M, Kunze AE (2020) Telephoneguided imagery rehearsal therapy for nightmares: efficacy and mediator of change. J Sleep Res. https://doi.org/10.1111/jsr.13123

23. Schredl M, Lüth K, Schmitt J (2020) Changes in nightmare frequency and nightmare distress after CPAP initiation in patients with obstructive sleep

\section{Überwindung von Albträumen am Telefon: einmalige telefonische Beratung mit Einsatz der Imagery Rehearsal Therapy}

Hintergrund: Da Menschen mit Albträumen nur selten Hilfe suchen und oftmals unbehandelt bleiben, werden niedrigschwellige Interventionen und Selbsthilfemethoden benötigt. Unter verschiedenen Behandlungsansätzen für Albträume ist die Imagery Rehearsal Therapy (IRT) die Therapie der Wahl.

Ziel der Arbeit: In der aktuellen Studie wurde getestet, ob die IRT auch dann wirksam ist, wenn sie in einer Kurzversion im Rahmen einer einmaligen telefonischen Beratung angewendet wird.

Methoden: Untersucht wurden die Albtraumhäufigkeit und die Albtraumbelastung von 28 Teilnehmenden vor und nach einer telefonischen Beratung. Die 30-minütige Sitzung beinhaltete Informationen zur Albtraum-Ätiologie sowie eine Kurzform der IRT. Im Anschluss an die Sitzung erfolgte eine 8-wöchige Selbstübungsphase. Die Teilnehmenden waren entweder Teil einer Studierendengruppe oder Teil einer Gruppe von Patient*innen aus einem Schlaflabor. Es wurden Unterschiede innerhalb der Gruppen und zwischen den Gruppen untersucht. Eine Kontrollgruppe gab es nicht. Ergebnisse: Die Albtraumhäufigkeit und die Albtraumbelastung waren im Vorhernachher-Vergleich in der Gesamtstichprobe und in beiden individuell analysierten Stichproben signifikant reduziert. Die Effektgrößen sind sehr hoch im Vergleich zu denen der Wartelisten-Kontrollgruppen ähnlicher Studien.

Schlussfolgerung: Die Autor*innen wiesen nach, dass eine kurze telefonische Intervention ausreichen kann, um eine signifikante Linderung von Albträumen zu erreichen. Dieser Ansatz bietet eine niedrigschwellige Intervention für Betroffene und sollte daher Einzug in die klinische Praxis erhalten.

\section{Schlüsselwörter}

Parasomnien · Träume · Distress · Therapieadhärenz und -compliance · Schlaf-Wach-Störungen

apnea syndrome: An observational study. International Journal of Dream Research 13:297-301. https://doi.org/10.11588/ijodr.2020.2.73791

24. Stumbrys T, Erlacher D, SchredI M (2013) Reliability and stability of lucid dream and nightmare frequency scales. Int J Dream Res 6:53-56. https:// doi.org/10.11588/ijodr.2013.2.11137

25. Schredl M, Berres S, Klingauf A, Schellhaas S, Göritz AS (2014) The Mannheim dream questionnaire (MADRE): retest reliability, age and gender effects. Int J Dream Res 7:141-147. https://doi.org/ 10.11588/ijodr.2014.2.16675

26. Schredl M (2013) Träume - Unser nächtliches Kopfkino, 2nd edn. Springer Spektrum, Berlin

27. Fritz CO, Morris PE, Richler JJ (2012) Effect size estimates: Current use, calculations, and interpretation. J Exp Psychol Gen 141:2-18. https://doi.org/10.1037/a0024338

28. Cohen J (1988) Statistical power analysis for the behavioral sciences, 2nd edn. Erlbaum, Hillsdale

29. Kellner R, Neidhardt J, Krakow B, Pathak D (1992) Changes in chronic nightmares after one session of desensitization or rehearsal instructions. Am J Psychiatry 149:659-663. https://doi.org/10.1176/ ajp.149.5.659

30. Krakow B, Hollifield $M$, Johnston $L$, Koss $M$, Schrader R, Warner TD, Tandberg D, Lauriello J, Mcbride L, Cutchen L, Cheng D, Emmons S, Germain A, Melendrez D, Sandoval D, Prince H (2001) Imagery rehearsal therapy for chronic nightmares in sexual assault survivors with posttraumatic stress disorder. JAMA 286:537-545. https://doi.org/10.1001/jama.286.5.537
31. Krakow B, Kellner R, Neidhardt J, Pathak D, Lambert $L$ (1993) Imagery rehearsal treatment of chronic nightmares: with a thirty month follow-up. J Behav Ther Exp Psychiatry 24:325-330. https:// doi.org/10.1016/0005-7916(93)90057-4

32. BaHammam AS, Al-Shimemeri SA, Salama RI, Sharif MM (2013) Clinical and polysomnographic characteristics and response to continuous positive airway pressure therapy in obstructive sleep apnea patients with nightmares. Sleep Med 14:149-154. https://doi.org/10.1016/j.sleep.2012. 07.007

33. Krakow B, Kellner R, Pathak D, Lambert $L$ (1995) Imagery rehearsal treatment for chronic nightmares. Behav Res Ther 33:837-843. https:// doi.org/10.1016/0005-7967(95)00009-M 